\title{
Influence of Azo Dye on Metabolism of Phosphorus Accumulating Organisms Linked to Transformation of Intracellular Storage Products
}

\author{
Fang Fang1,2, Hui Chen'1, Jing-Yang Luo ${ }^{1 *}$, Zhe-Ying Zhu' ${ }^{1}$, Jia-Shun Cao1 \\ ${ }^{1}$ Key Laboratory of Integrated Regulation and Resource Development on Shallow Lakes, Ministry of Education, College of \\ Environment, Hohai University, Nanjing, China \\ ${ }^{2}$ Guangzhou Key Laboratory of Environmental Exposure and Health, School of Environment, Jinan University, Guangzhou, China \\ Email: *luojy2016@hhu.edu.cn
}

How to cite this paper: Fang, F., Chen, H., Luo, J.-Y., Zhu, Z.-Y. and Cao, J.-S. (2018) Influence of Azo Dye on Metabolism of Phosphorus Accumulating Organisms Linked to Transformation of Intracellular Storage Products. Journal of Geoscience and Environment Protection, 6, 1-10. https://doi.org/10.4236/gep.2018.65001

Received: April 9, 2018

Accepted: May 6, 2018

Published: May 9, 2018

Copyright $\odot 2018$ by authors and Scientific Research Publishing Inc. This work is licensed under the Creative Commons Attribution International License (CC BY 4.0).

http://creativecommons.org/licenses/by/4.0/

(c) (i) Open Access

\begin{abstract}
In this study, the influence of azo dye of methyl red (MR) on COD, dye and phosphorus removal and the transformation of polyhydroxyalkanoate (PHA) and glycogen of phosphate accumulating organisms in enhanced biological phosphorus removal (EBPR) system were investigated. The results indicated COD and dye removal efficiencies were decreased from $97.9 \%$ to $72.8 \%$ and $99.7 \%$ to $82.0 \%$, respectively, when MR concentration was increased from 0 to $40 \mathrm{mg} / \mathrm{L}$. Low MR concentration $(5 \mathrm{mg} / \mathrm{L})$ had no influence on P removal and transformation of PHA and glycogen. However, P removal, PHA production and consumption, and glycogen replenishment were seriously inhibited at high MR concentration, while glycogen hydrolysis was simulated at MR concentration of 20 and $40 \mathrm{mg} / \mathrm{L}$. The transformations of PHA and glycogen at aerobic condition were more sensitive to those at anaerobic condition at high MR concentration. These results demonstrated dye and its intermediate products would inhibit the metabolism of polyphosphate accumulating organisms, which should be taken into account in future work.
\end{abstract}

\section{Keywords}

Activated Sludge, Enhanced Biological Phosphorus Removal (EBPR),

Glycogen, Methyl Red (MR), Polyhydroxyalkanoate (PHA)

\section{Introduction}

Enhanced biological phosphorus removal (EBPR) process is considered as one of 
the most economical and sustainable methods for phosphorus removal in wastewater treatment plants [1] [2]. In this process, activated sludge was under the alternating anaerobic and aerobic conditions and polyphosphate accumulating organisms (PAOs) could be enriched in this system. Generally, under anaerobic conditions, PAOs take up volatile fatty acids and store them to intracellular polyhydroxyalkanotes (PHAs), with the energy obtained from glycogen utilization and poly-phosphate (poly-P) hydrolysis and simultaneously released of ortho-phosphorus into solution. However, under aerobic conditions, PAOs take up excess phosphorus as intracellular poly-P formation and simultaneously glycogen is replenished by the oxidation of stored PHA. With wasted activated sludge enriched in poly-P discharging, the net removal of phosphorus in activated sludge can be achieved [1].

In EBPR system, many operational factors would influence the performance of this system, especially the variation of the wastewater quality. At present, much municipal wastewater often contains large amount of industrial wastewater, especially includes certain amount of heavy metals, dyes and antibiotics, which has detrimental effect on nutrient removal [2]. For example, poor performance of P removal in EBPR system had been found to be related with the presence of heavy metals or antibiotics in wastewater [3]-[9]. However, few studies have been considered the influence of dye, especially azo dye on EBPR system performance.

In activated sludge system, azo dye is often complete removed under sequencing anaerobic-aerobic biological treatment process [10]. Under anaerobic conditions, with the help of azoreductase enzymes, reductive cleavage of the azo bonds resulted in the formation of potentially hazardous aromatic amines. Then under aerobic conditions, the produced aromatic amines can be further degraded [11] [12] [13] [14]. The azo dyes or their cleavage products would change the characteristics of sludge or had biological toxicity on microorganisms [15]. However, the influence of dye on the performance of EBPR system is still unknown yet.

Therefore, in this study, the influence of azo dye of methyl med (MR) on EBPR system were investigated. The COD, phosphorus and dye removal as well as intracellular storage products of PHA and glycogen were evaluated at different dye concentrations. Hopefully, the results would provide a better understanding of dye on EBPR system.

\section{Materials and Methods}

\subsection{Reactor, Sludge and Wastewater}

An anaerobic-aerobic sequencing batch reactor (SBR) with a working volume of 3.2 $\mathrm{L}$ was used for the cultivation of activated sludge. The reactor was operated with a cycle time of $12 \mathrm{~h}$, consisted of 7 min of influent filling, $6 \mathrm{~h}$ of anaerobic, 5 $\mathrm{h}$ of aeration, $40 \mathrm{~min}$ of settling, $7 \mathrm{~min}$ of effluent withdrawal and $6 \mathrm{~min}$ of standing idle. The hydraulic retention time (HRT) and the sludge retention time 
(SRT) were set at $24 \mathrm{~h}$ and 12 days, respectively. Nitrogen gas was purged into the reactor with mechanical mixing for anaerobic conditions. Air was introduced through an air diffuser by an air pump for aeration. The temperature was kept at $25^{\circ} \mathrm{C}$ with water jacket. The azo dye of MR was introduced to activated sludge gradually from 5 to $40 \mathrm{mg} / \mathrm{L}$.

The seed sludge was obtained from a secondary sedimentation tank of the sewage treatment station in Han Bai Textile Company, Nanjing, China. The seed sludge had a mixed liquor suspended solids (MLSS) concentration of about 3000 $\mathrm{mg} / \mathrm{L}$. Synthetic wastewater used in this work comprised $(\mathrm{mg} / \mathrm{L})$ : sodium acetate $1000, \mathrm{NH}_{4} \mathrm{Cl} 170, \mathrm{CaCl}_{2} \cdot 2 \mathrm{H}_{2} \mathrm{O} 7.5, \mathrm{NaH}_{2} \mathrm{PO}_{4} 48, \mathrm{MgCl}_{2} 11$, and $\mathrm{KCl} 25$. In addition, $2.5 \mathrm{~mL}$ microelement solution was added, which contained (mg/L): $\mathrm{H}_{3} \mathrm{BO}_{3}$ 2, $\mathrm{FeCl}_{2} \cdot 4 \mathrm{H}_{2} \mathrm{O}$ 2, EDTA 2, $\mathrm{ZnCl}_{2} \cdot 4 \mathrm{H}_{2} \mathrm{O}$ 0.4, $\mathrm{MnCl}_{2} \cdot 4 \mathrm{H}_{2} \mathrm{O} 0.8, \mathrm{CuCl}_{2} \cdot 2 \mathrm{H}_{2} \mathrm{O} 0.2$, $\left(\mathrm{NH}_{4}\right)_{6} \mathrm{MoO}_{7} \cdot 4 \mathrm{H}_{2} \mathrm{O} 1.1$ and $\mathrm{NiCl}_{2} \cdot 6 \mathrm{H}_{2} \mathrm{O} 1$.

\subsection{Batch Experiments}

The batch experiments were carried out in a $2.0 \mathrm{~L}$ batch reactor. When the reactor reached the steady state, the activated sludge with a mixed liquor volatile suspended solids (MLVSS) of 2700 - $2800 \mathrm{mg} / \mathrm{L}$ was withdrawn from the SBR to batch reactor after starved for several hours and then washed twice with distilled water. A required amount of MR solution was added to batch reactors at the beginning of cycle to provide a constant MR concentration of 5, 10, 20, and 40 $\mathrm{mg} / \mathrm{L}$ for each treatment cycle, respectively. The reactor without MR was used as the control. The influent chemical oxygen demand (COD) concentration was $400 \mathrm{mg} / \mathrm{L}$ and the medium $\mathrm{pH}$ was adjusted at around 7.0 through the addition of $1 \mathrm{M} \mathrm{HCl}$ or $\mathrm{NaOH}$. The argon gas was filled into the synthetic wastewater for $20 \mathrm{~min}$ to remove the oxygen before into the reactor. In the aerobic condition, the SBR was aerated continuously to keep the dissolved oxygen (DO) concentration around $6 \mathrm{mg} / \mathrm{L}$. Samples of the activated sludge mixture were withdrawn from the reactor at set intervals for the analysis of COD, dye, phosphorus, and intracellular storage products of PHA and glycogen.

\subsection{Analytical Methods}

The measurements of COD, phosphorus $\left(\mathrm{PO}_{4}{ }^{3-}-\mathrm{P}\right), \mathrm{MLSS}$, and MLVSS were conducted according to the Standard Methods [16]. The concentration of azo dye was determined using the modified method of Wong and Yuen [17]. Aliquots from the test solution were centrifuged at $5200 \mathrm{rpm}$ for $5 \mathrm{~min}$. The dye solution was measured at $430 \mathrm{~nm}$, which is the absorbance maximum for the orange color of methyl red, using a spectrophotometer (ALPHA-1506, Pu Yuan, China).

The PHA was determined according to Fang et al. [18], and glycogen was measured according to Smolders et al. [19] with minor modification. Glycogen was extracted and hydrolyzed from activated sludge by heating a sample of a known amount of freeze-dried activated sludge (typically $50 \mathrm{mg}$ ) in a known 
volume of $0.6 \mathrm{M} \mathrm{HCl}$ (typically $5 \mathrm{~mL}$ ) for $5 \mathrm{~h}$ at $100^{\circ} \mathrm{C}$. The glycogen content in the supernatant was determined by anthrone method [20] with glucose as the standard.

\section{Results and Discussion}

\subsection{COD and Dye Removal at Different Dye Concentration}

The influences of dye on COD and dye removal efficiencies are shown in Figure 1. At the MR concentration of $5 \mathrm{mg} / \mathrm{L}$, the COD removal efficiency was almost the same as that in control experiment. However, with the increase of MR concentration, COD removal efficiency decreased slightly. The increase of MR concentration from 0 to $40 \mathrm{mg} / \mathrm{L}$ led to the decrease of COD removal efficiency from $97.9 \%$ to $84.0 \%$ (Figure 1(a)). The inhibition of PAOs and other heterotrophic microorganisms might be the reason for this phenomenon.

The dye removal efficiency was also decreased from $99.7 \%$ to $86.9 \%$ with the increase of MR concentration from 5 to $40 \mathrm{mg} / \mathrm{L}$ (Figure 1(b)), and the result was consistent with that reported by Hakimelahi et al. [21]. The decrease of dye removal efficiency was probably due to the lessening of the COD removal caused a lower production of reducing equivalents, negatively affecting the color removal [22]. Furthermore, main color was removed at the anaerobic condition and the contribution of aerobic condition to decolorization was low. The results were in good agreement with other results in the sequencing anaerobic-aerobic conditions [13] [23].

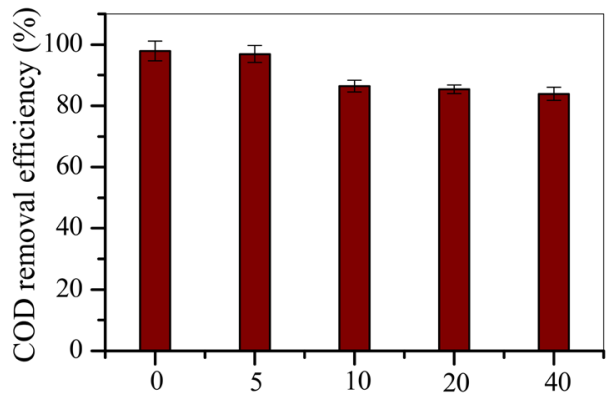

(a)

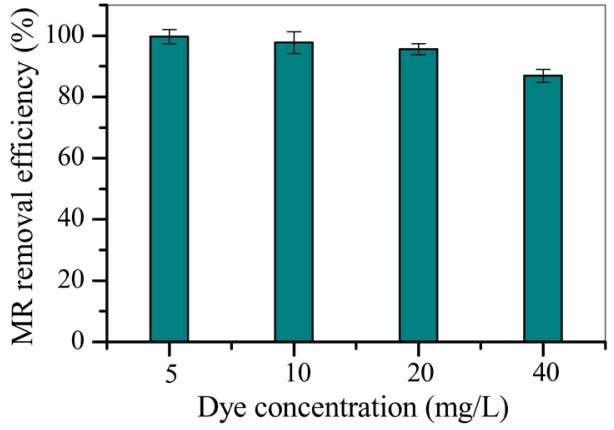

(b)

Figure 1. Effects of dye concentration on COD and dye removal: (a) COD removal efficiency; and (b) MR removal efficiency. 
To further confirm the biodegradation of MR by activated sludge, the UV-Vis spectra of the samples taken at different time are illustrated in Figure 2. The peak in the visible region at $430 \mathrm{~nm}$ which represents the azo linkage of MR was decreased at anaerobic condition. Correspondingly, the appearance of the absorbance peak at $241 \mathrm{~nm}$ and $305 \mathrm{~nm}$ is probably due to the production of intermediate products of $N, N^{*}$ dimethyl-p-phenyle-nediamine (DMPD) and 2 -aminobenzoic acid (2-ABA) [24]. At aerobic condition, the two absorbance peaks were decreased. This indicated that the ability of the activated sludge for the biodegradation of MR.

\subsection{Influence of Dye Concentration on P Release and Uptake}

The $\mathrm{P}$ release at anaerobic condition and $\mathrm{P}$ uptake at aerobic condition at different MR concentrations are shown in Figure 3. It was found that $P$ removal efficiency was almost $100 \%$ in the control experiment. At low MR concentration of $5 \mathrm{mg} / \mathrm{L}$, the $\mathrm{P}$ release and uptake were almost the same as those in control experiments, which indicated that low MR concentration had no inhibitory effect on $\mathrm{P}$ removal in the EBPR system. At MR concentration of $10 \mathrm{mg} / \mathrm{L}$, P removal efficiency decreased slightly to $93.6 \%$. However, when MR concentration was further increased to 20 and $40 \mathrm{mg} / \mathrm{L}$, P removal efficiency decreased to $59.9 \%$ and $19.9 \%$, respectively. Under anaerobic conditions, P release decreased significantly at MR concentration of 20 and $40 \mathrm{mg} / \mathrm{L}$, suggesting that polyphosphate degradation was inhibited at high MR concentration [3]. Correspondingly, $\mathrm{P}$ uptake at aerobic condition was inhibited due to the shortage of energy provided by PHA degradation [25]. Thus, the increase of MR concentration severely decreased P removal capacity and had a toxic effect on the activity of PAOs.

\subsection{Influence of Dye Concentration on the Transformation of PHA}

The changes of intracellular storage product of PHA at anaerobic condition at different MR concentrations are illustrated in Figure 4. Under the control experiment, the content of PHA stored at anaerobic condition was $152.4 \mathrm{mg} / \mathrm{gVSS}$. With the increase of MR concentration from 5 to $40 \mathrm{mg} / \mathrm{L}$, the content of PHA stored at anaerobic condition decreased from 147.2 to $79.0 \mathrm{mg} / \mathrm{gVSS}$. The linear regression analysis indicated that the stored PHA content at anaerobic condition was linearly decreased with the increase in MR concentration $\left(R^{2}=0.978\right)$. The results indicated that high dye concentration could inhibit the PHA synthesis at anaerobic condition in EBPR system, especially at high MR concentration. Due to the inhibitions of high concentration of intermediate aromatic amide on substrate uptake and poly-phosphate degradation at anaerobic condition, insufficient energy available can be used for PHA synthesis, leading to less PHA stored at higher MR concentration [1] [5].

Figure 4 also gives the content of PHA degradation at aerobic condition with different concentrations of MR. The content of PHA consumption at aerobic condition was $146.8 \mathrm{mg} / \mathrm{gVSS}$ for the control experiment, and similar PHA degradation 


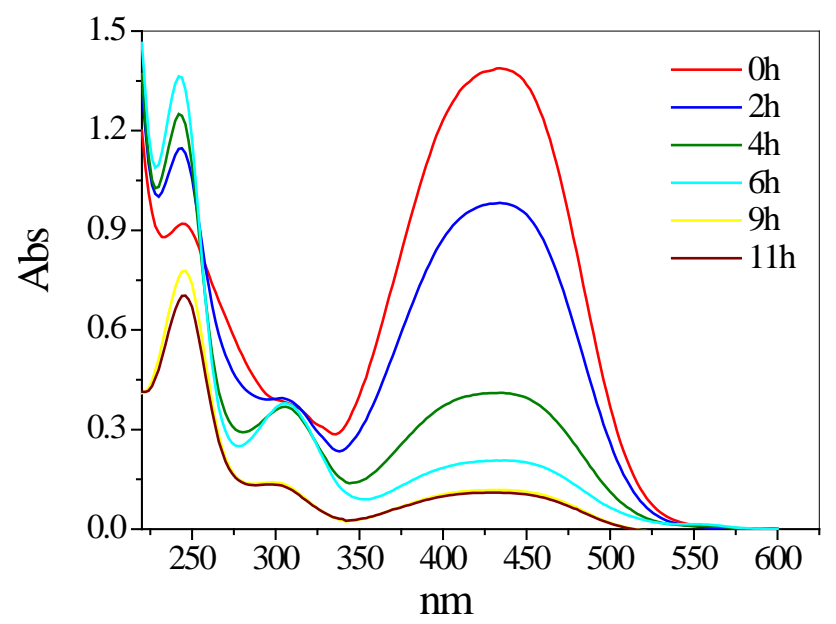

Figure 2. UV-Vis spectra analysis of MR at anaerobic and aerobic conditions.

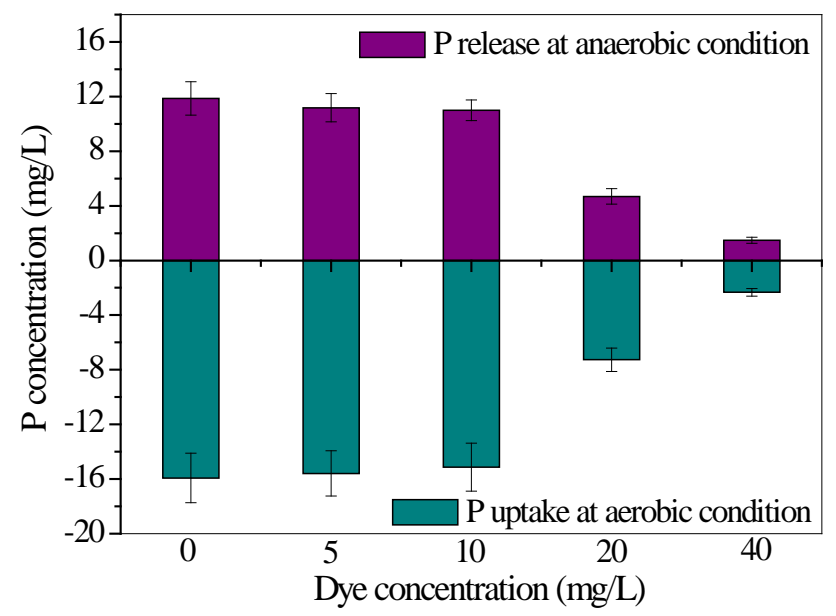

Figure 3. The $\mathrm{P}$ release and uptake in batch experiments at different MR concentrations.

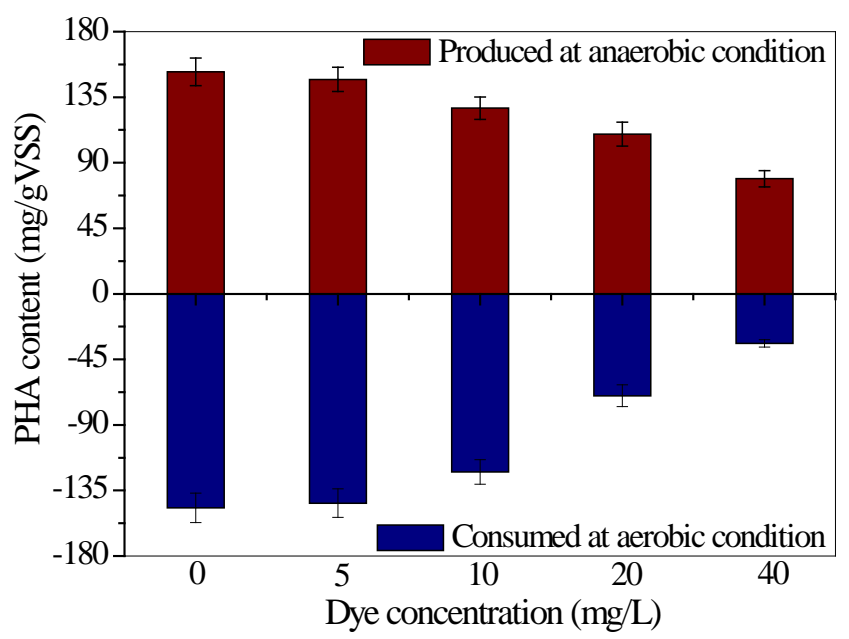

Figure 4. The transformation of PHA in batch experiments at different MR concentrations. 
was displayed at MR concentration of $5 \mathrm{mg} / \mathrm{L}$. However, with the increase of MR concentration from 10 to $40 \mathrm{mg} / \mathrm{L}$, PHA degradation content decreased sharply, indicating that high concentration of MR had severely inhibition effect on PHA degradation at aerobic condition. The results demonstrated that the mechanism of aerobic PHA degradation was more sensitive to MR dosing than that of anaerobic PHA synthesis, which was in agreement with the findings of Tsai and Chen [4] and Wang et al. [5].

\subsection{Influence of Dye Concentration on the Transformation of Glycogen}

Figure 5 depicts the variation of intracellular storage product of glycogen at different MR concentrations. Under the control experiment, the hydrolyzed-glycogen was $46.7 \mathrm{mg} / \mathrm{g}$ VSS at anaerobic condition. At low MR concentrations ( 5 and $10 \mathrm{mg} / \mathrm{L}$ ), the amount of glycogen hydrolysis at anaerobic condition was similar with that in the control experiment, indicating that low concentration of MR had no effect on the hydrolysis of glycogen at anaerobic condition in EBPR system. However, glycogen contents at anaerobic condition increased when dye concentrations were increased from 20 and $40 \mathrm{mg} / \mathrm{L}$. The higher glycogen content at anaerobic condition was probably due to the maintenance adenosine triphosphate required by the cell [5].

At aerobic condition, the content of glycogen was $54.9 \mathrm{mg} / \mathrm{g}$ VSS for the control experiment (Figure 5). At low MR concentrations (5 and $10 \mathrm{mg} / \mathrm{L}$ ), the content of glycogen at aerobic condition was similar with that in the control experiment, indicating that low concentration of MR had no effect on glycogen replenishment at aerobic condition in EBPR system. However, the glycogen content decreased sharply at MR concentrations of 20 and $40 \mathrm{mg} / \mathrm{L}$. Due to the accumulated PHA at anaerobic condition decreased at high MR concentration, less available PHA could be used for glycogen reproduction, resulting in the decrease in glycogen content [3].

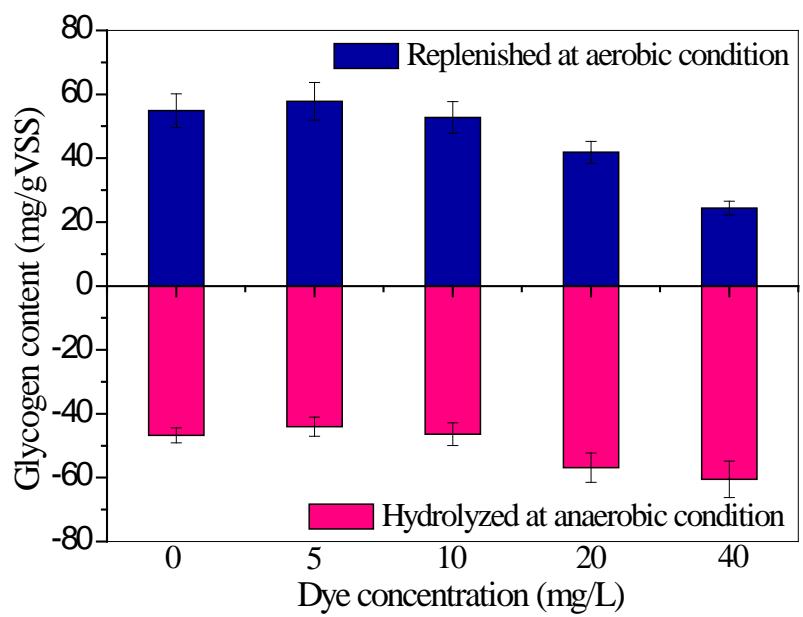

Figure 5. The transformation of glycogen in batch experiments at different MR concentrations. 


\section{Conclusion}

The pollution removal and transformation of PHA and glycogen at different MR concentrations in EBPR system were investigated in this study. The COD, dye and phosphorus removal efficiencies were all decreased with the increase of MR concentration. For intracellular storage products, PHA synthesis and consumption, and glycogen replenishment was seriously inhibited at high MR concentration. Oppositely, glycogen hydrolysis was increased at MR concentration of 20 and $40 \mathrm{mg} / \mathrm{L}$. The transformations of PHA and glycogen at aerobic condition were more sensitive to high MR concentration than those at anaerobic condition.

\section{Acknowledgements}

The work is financially supported by the "Fundamental Research Funds for the Central Universities, No: 2017B13214", "National Natural Science Foundation of China (No: 51578210)", "Guangzhou Key Laboratory of Environmental Exposure and Health (No. GZKLEEH201603)" and the "Priority Academic Program Development of Jiangsu Higher Education Institutions (PAPD), China".

\section{References}

[1] Oehmen, A., Lemos, P.C., Carvalho, G., Yuan, Z.G., Keller, J., Blackall, L.L. and Reis, M.A.M. (2007) Advances in Enhanced Biological Phosphorus Removal: From Micro to Macro Scale. Water Research, 41, 2271-2300.

https://doi.org/10.1016/j.watres.2007.02.030

[2] Zheng, X.L., Sun, P.D., Han, J.Y., Song, Y.Q., Hu, Z.R., Fan, A.Q. and Lv, S.Y. (2014) Inhibitory Factors Affecting the Process of Enhanced Biological Phosphorus Removal (EBPR)-A Mini-Review. Process Biochemistry, 49, 2207-2213. https://doi.org/10.1016/j.procbio.2014.10.008

[3] Sun, J., Wang, D.B., Wang, S.N., Chen, F., Zhong, Y., Yi, K.X., Yao, F.B., Jiang, C., Li, S.B., Li, X.M. and Zeng, G.M. (2017) Nickel Toxicity to the Performance and Microbial Community of Enhanced Biological Phosphorus Removal System. Chemical Engineering Journal, 313, 415-423. https://doi.org/10.1016/j.cej.2016.12.078

[4] Tsai, Y.P. and Chen, H.T. (2011) Influence of Sludge Retention Time on Tolerance of Copper Toxicity for Polyphosphate Accumulating Organisms Linked to Polyhydroxyalkanoates Metabolism and Phosphate Removal. Bioresource Technology, 102, 11043-11047. https://doi.org/10.1016/j.biortech.2011.09.050

[5] Wang, Y.Y., Ren, Z.J., Jiang, F., Geng, J.J., He, W.T. and Yang, J. (2011) Effect of Copper Ion on the Anaerobic and Aerobic Metabolism of Phosphorus-Accumulating Organisms Linked to Intracellular Storage Compounds. Journal of Hazardous Materials, 186, 313-319. https://doi.org/10.1016/j.jhazmat.2010.11.007

[6] You, S.J., Tsai, Y.P., Cho, B.C. and Chou, Y.H. (2011) Metabolic Influence of Lead on Polyhydroxyalkanoates (PHA) Production and Phosphate Uptake in Activated Sludge Fed with Glucose or Acetic Acid as Carbon Source. Bioresource Technolo$g y ., 102,8165-8170$. https://doi.org/10.1016/j.biortech.2011.06.022

[7] Zheng, X., Wu, R. and Chen, Y.G. (2011) Effects of ZnO Nanoparticles on Waste- 
water Biological Nitrogen and Phosphorus Removal. Environmental Science \& Technology, 45, 2826-2832. https://doi.org/10.1021/es2000744

[8] Hu, Z.T., Sun, P.D., Hu, Z.R., Han, Y.J., Wang, R.Y., Jiao, L. and Yang, P.F. (2016) Short-Term Performance of Enhanced Biological Phosphorus Removal (EBPR) System Exposed to Erythromycin (ERY) and Oxytetracycline (OTC). Bioresource Technology, 221, 15-25. https://doi.org/10.1016/j.biortech.2016.08.102

[9] Hu, Z.T., Sun, P.D., Han, Y.J., Wang, R.Y., Jiao, L., Yang, P.F. and Cai, J. (2018) The Acute Effects of Erythromycin and Oxytetracycline on Enhanced Biological Phosphorus Removal System: Shift in Bacterial Community Structure. Environmental Science and Pollution Research, 25, 9342-9350. https://doi.org/10.1007/s11356-018-1221-1

[10] Popli, S. and Patel, U.D. (2015) Destruction of Azo Dyes by Anaerobic-Aerobic Sequential Biological Treatment: A Review. International Journal of Environmental Science and Technology, 12, 405-420. https://doi.org/10.1007/s13762-014-0499-x

[11] Van der Zee, F.P. and Villaverde, S. (2005) Combined Anaerobic-Aerobic Treatment of Azo Dyes-A Short Review of Bioreactor Studies. Water Research, 39, 1425-1440. https://doi.org/10.1016/j.watres.2005.03.007

[12] Saratale, R.G., Saratale, G.D., Kalyani, D.C., Chang, J.S. and Govindwar, S.P. (2011) Bacterial Decolorization and Degradation of Azo Dyes: A Review. Journal of the Taiwan Institute of Chemical Engineers, 42, 138-157. https://doi.org/10.1016/j.jtice.2010.06.006

[13] Koupaie, E.H., Moghaddam, M.R.A. and Hashemi, S.H. (2013) Evaluation of Integrated Anaerobic/Aerobic Fixed-Bed Sequencing Batch Bioflilm Reactor for Decolorization and Biodegradation of Azo Dye Acid Red 18: Compassion of Using Two Types of Packing Media. Bioresource Technology, 127, 415-421. https://doi.org/10.1016/j.biortech.2012.10.003

[14] Murali, V., Ong, S.A., Ho, L.N. and Wong, Y.S. (2013) Evaluation of Integrated Anaerobic-Aerobic Bioflim Reactor for Degradation of Azo Dye Methyl Orange. Bioresource Technology, 143, 104-111. https://doi.org/10.1016/j.biortech.2013.05.122

[15] Dai, R.B., Chen, X.G., Luo, Y., Ma, P.Y., Ni, S.S., Xiang, X.Y. and Li, G. (2016) Inhibitory Effect and Mechanism of Azo Dyes on Anaerobic Methanogenic Wastewater Treatment: Can Redox Mediator Remediate the Inhibition? Water Research, 104, 408-417. https://doi.org/10.1016/j.watres.2016.08.046

[16] APHA, AWWA, WEF (2005) Standard Methods for the Examination of Water and Wastewater. 21st Edition, American Public Health Association, Washington DC.

[17] Wong, R.K. and Yuen, P.Y. (1996) Decolourization and Biodegradation of Methyl Red by Klebsiella pneumoiae RS-13. Water Research, 30, 1736-1744. https://doi.org/10.1016/0043-1354(96)00067-X

[18] Fang, F., Liu, X.W., Xu, J., Yu, H.Q. and Li, Y.M. (2009) Formation of Aerobic Granules and Their PHB Production at Various Substrate and Ammonium Concentrations. Bioresource Technology, 100, 59-63.

https://doi.org/10.1016/j.biortech.2008.06.016

[19] Smolders, G.J.F., van der Meij, J., van Loosdrecht, M.C.M. and Heijnen, J.J. (1994) Model of the Anaerobic Metabolism of the Phosphorus Removal Process, Stoichiometry and $\mathrm{pH}$ Influence. Biotechnology and Bioengineering, 43, 461-470. https://doi.org/10.1002/bit.260430605

[20] Raunkjaer, K., Hvitved-Jacobsen, T. and Nielsen, P.H. (1994) Measurements of 
Pools of Protein, Carbohydrate and Lipid in Domestic Waste-Water. Water Research, 28, 251-262. https://doi.org/10.1016/0043-1354(94)90261-5

[21] Hakimelahi, M., Moghaddam, M.R.A. and Hashemi, S.H. (2012) Biological Treatment of Wastewater Containing an Azo Dyes using Mixed Culture in Alternating Anaerobic/Aerobic Sequencing Batch Reactors. Biotechnology and Bioprocess Engineering, 17, 875-880. https://doi.org/10.1007/s12257-011-0673-7

[22] Farabegoli, G., Chiavola, A., Rolle, E. and Naso, M. (2010) Decolorization of Reactive Red 195 by Mixed Culture in an Alternating Anaerobic-Aerobic Sequencing Batch Reactor. Biochemical Engineering Journal, 52, 220-226. https://doi.org/10.1016/j.bej.2010.08.014

[23] Kapdan, I.K. and Ozturk, R. (2005) Effect of Operating Parameters on Color and COD Removal Performance of SBR: Sludge Age and Initial Dyestuff Concentration. Journal of Hazardous Materials, 123, 217-222. https://doi.org/10.1016/j.jhazmat.2005.04.013

[24] Zhao, M., Sun, P.F., Du, L.N., Wang, G., Jia, X.M. and Zhao, Y.H. (2014) Biodegradation of Methyl Red by Bacillus sp. Strain UN2: Decolorization Capacity, Metabolites Characterization, and Enzyme Analysis. Environmental Science and Pollution Research, 21, 6136-6145. https://doi.org/10.1007/s11356-014-2579-3

[25] Fang, J., Sun, P.D., Xu, S.J., Luo, T., Lou, J.Q., Han, J.Y. and Song, Y.Q. (2012) Impact of $\mathrm{Cr}(\mathrm{VI})$ on P Performance in Enhanced Biological Phosphorus Removal (EBPR) System Based on the Anaerobic and Aerobic Metabolism. Bioresource Technology, 121, 379-385. https://doi.org/10.1016/j.biortech.2012.07.001 